\title{
Nature-Based "Satoyama"
} Tourism Satisfaction Model: An Examination of Motivation as a Mediator in Domestic and International Tourists in Japan

\author{
Lilia Shahar Griffin \\ Graduate School of Global Environmental Studies, Kyoto University, Kyoto, Japan \\ Email: griffinlilias@gmail.com
}

How to cite this paper: Griffin, L. S. (2021). Nature-Based "Satoyama" Tourism Satisfaction Model: An Examination of Motivation as a Mediator in Domestic and International Tourists in Japan. Open Journal of Social Sciences, 9, 380-393.

https://doi.org/10.4236/jss.2021.910027

Received: October 1, 2021

Accepted: October 26, 2021

Published: October 29, 2021

Copyright $\odot 2021$ by author(s) and Scientific Research Publishing Inc. This work is licensed under the Creative Commons Attribution International License (CC BY 4.0).

http://creativecommons.org/licenses/by/4.0/

\begin{abstract}
This research examines whether the tourists' culture affects their motivation and satisfaction when visiting nature-based tourism (NBT) destinations in Japan. An analysis was conducted in order to examine the mediating effect of motivation on the correlation between tourist group (domestic and international tourists) and their satisfaction from a nature-based tourism experience in Japan. Data from 181 domestic and 177 international tourists was collected via a questionnaire survey in two locations: Kayabuki no Sato in Miyama, and Ogimachi in Shirakawa-go. While domestic travelers are Japanese, international travelers are a varied group from over twenty countries, mostly from the East Asian region. The participants filled a motivation as well as a satisfaction questionnaire and sample was done randomly. Results verify the hypothesis that motivation highly influences the satisfaction from the visit, and it fully mediates the correlation between the tourist group and satisfaction, when Japanese tourists show lower satisfaction and motivation compared to international tourists. A further analysis of the results highlights the differences in the push factors between the domestic and international tourists, as well as the high number of elder domestic tourists. Proposals for better tourist retention strategies for local authorities and stakeholders were presented based on the findings.
\end{abstract}

\section{Keywords}

Nature-Based Tourism, Satoyama, Dimensions of National Culture, Japan, Comparative Study 


\section{Nature Based Tourism (NBT) in Japan}

The differences between tourists of different countries in their perception of tourism were large studied (Haahti \& Yavas, 1983; Batra, 2008; Stone \& Nyaupane, 2019). The perception of different factors of the tourism experience creates various expectations, which in turn, affect the satisfaction from the visit. In the case of Nature-Based Tourism (NBT) in Japan, it is expected that the social, and cultural background of the visitors will greatly influence the satisfaction during the visit, as found in various previous studies. Hence, the satisfaction is expected to be different between the domestic Japanese tourists and international tourists. Moreover, the cultural background is also a key factor in realizing the motivation to visit a tourism destination or purpose in the first place, and is greatly different from one culture to another, as many studies have shown in the past (Brown, 2005). However, the role of motivation in the tourists' satisfaction is not yet to be studied, nor any comparison between domestic and international tourists' motivation and satisfaction towards NBT experience in Japan. This article focuses on the cultural influence over the motivation and satisfaction of nature-based tourists in Japan and aims to shed light on the best practices for the NBT industry in Japan.

NBT is an umbrella term that refers to the destination choice of visitors (Boo, 1990) and their activities in the destination (Sung, Morrison, \& O'leary, 2000). In recent years, NBT has received high recognition as being beneficial for personal, communal, and environmental purposes. It was found to increase travelers' well-being, support local communities' income, and develop conservation consciousness (Hartig et al., 2014; Frumkin et al., 2017; Wolsko, Lindberg, \& Reese, 2019). Consequently, many countries have set goals to promote NBT. While domestic tourism plays a significant role in Japan's NBT, in recent years, inbound tourists have also started to show greater interest in participating in this form of tourism (Fujita et al., 2017). Tourism choices as destination preferences, length of stay and activities to participate in represent not only the individual but also their culture. Therefore, to understand tourism trends and NBT in particular, it is important to first comprehend the tourists' cultural background and how it affects their motivation. Both the international and domestic tourists' motivation and satisfaction from the experience and the differences between the two groups in these realms have been little studied in Satoyama settings. While previous studies found that satisfaction is created, to some extent, by motivation (Ross \& Iso-Ahola, 1991; Meng, Tepanon, \& Uysal, 2008; Oh \& Lee, 2017), however did not investigate the cultural formation of drives that influence tourists to participate NBT, this research aims to clearly portray the international and domestic tourists' perspectives while participating in an NBT experience in Japan, examine the differences in satisfaction level between them, and inspect the motivation as a mediator between the tourist group and the satisfaction. These measurements should be beneficial for policy makers and tourism managements institutions to make better strategies for destination promotion.

In Japan, a country with over $70 \%$ forest land and a large number of agricul- 
tural villages that face depopulation (Furukawa \& Tomokiyo, 2003), Agricultural Village-Stay Leisure Law was implemented in 1995. This law promoted touristic activities in rural areas, such as weekend-stays at farms (shümatsu nōhaku), day-trips for agricultural experiences (higaeri nögyō taiken), and local shops on rural road-sides (michi-no-eki). In 2007, Nature-Based Tourism was adopted by the Ministry of Agriculture, Forestry and Fisheries (MAFF) as a fundamental part of the Tourism Nation Promotion Basic Plan (Chakraborty \& Asamizu, 2014). The focus of NBT in Japan, from the government's point of view, is to promote agricultural villages and maintain the rural landscape, known in Japan as "Satoyama". Rural communities responded positively to this new trend of tourism, as it helped them protect villages from the effects of urban migration, aging, and decreased agricultural profitability (Hasan, 2017). Some farming households registered as minpaku (rural house-stay) to encourage visitors to stay longer and provide them with a new experience. Eventually, it helped the locals create an extra source of income.

While the hosts' motivation is clear, the tourists' motivation is also an important factor for the success of NBT. The latter is important to understand travel behavior. The motivation of Japanese people traveling to Satoyama areas is found to be related to their perception of the beauty of the trees in rural landscapes (Chen, Nakama, \& Zhang, 2017), and since the 1980s, a sense of nostalgia to the countryside in the light of high economic growth and massive urbanization (Hasan, 2017). However, international visitors may not have a similar sense of nostalgia for the Japanese rural landscape and might visit Satoyama destinations for different reasons. It has been evident in the past that international and domestic tourists had different interests when visiting the same destination in Japan (Maeda et al., 2018), yet the researches done on the difference between these two groups are limited. Shapoval et al. (2018) refer to international tourists' interest in Japan's rural landscape when they determined that the motivation of these tourists to return to Japan would be driven by the activities they were expecting from future visits, one of which is to visit acclaimed natural beauty. Still, the motivation of international tourists to visit Satoyama destinations could not be dismissed by only referring to their interest in acclaimed natural beauty. While attractions and amenities, access and mobility, destination marketing, and institutional factors as government tourism policy and international conditions are considered to be important factors of the inbound tourism development in Japan (Henderson, 2017), it seems that the motivation of inbound tourists to participate in NBT has not been examined sufficiently. Let alone, their satisfaction from this experience. The assumption that inbound tourists' will differ in their motivation and satisfaction from domestic tourists' relies on previous work that highlighted the differences in domestic and inbound tourists' perception of the same NBT destination (Stone \& Nyaupane, 2019).

When discussing the differences between domestic and inbound tourists in motivation and satisfaction, it is unavoidable to look into culture as a fundamental element that shapes the consumer-behavior. A number of studies at- 
tempted to investigate the differences in social behavior between different cultures (for example, Hall \& Hall, 1987; Triandis, 1989), when the cultural dimensions of Hofstede (1991) are one of the most widely used framework, and was found successful in distinguishing different cultures and their respective behavior. The framework consists of six dimensions; Power distance, individualism/collectivism, masculinity/femininity, uncertainty avoidance, long/short term orientation, and indulgence/restraint (Hofstede, 2011). The Japanese culture was found high in collectivism (in opposed to individualism), masculinity (in opposed to femininity), uncertainty avoidance, and long-term orientation compared to most other cultures discussed (Hofstede, 2001; Hofstede \& Minkov, 2010). As individuals that share the same culture are expected to also share similar attributes of consumer behavior, it is likely to find similarities in Japanese tourists' evaluations for tourism experience. Such similarities were found in previous studies in tourists of the same country regarding their perception of the destination, their activities, demographic profile, and their satisfaction level (Richardson \& Crompton, 1988; Danaher \& Arweiler, 1996; Armstrong et al., 1997). While culture is undoubtedly a fundamental element in tourists' motivation and satisfaction generation, looking into these elements' formation process will provide more comprehensive insights to understand tourists' NBT evaluation.

The formation of tourists' motivation, their perception of the tourism experience (the event), and eventually the effect are described in detail in Gnoth (1997) study. Although the framework does not intend to focus on the correlation between motivation and satisfaction specifically and explicitly, it can be argued that the satisfaction is one of the aspects of the effect formed by the tourism experience. According to Gnoth's framework, motive leads to an objective situation, which is influenced by values and perceptions, that together form the motivation. Therefore, the precursors to the motivation formation are key elements in the subjective experience of tourism. Then, the attitudes and the effect, which includes tourist's satisfaction, are not only an outcome of the motivation, as some studies attempted to address (Lee, Lee, \& Wicks, 2004; Ibrahim \& Gill, 2005; Devesa, Laguna, \& Palacios, 2010), but also of the motivation precursors such as values and perception, two elements that are integrally influenced by the individual's culture.

Following Gnoth (1997) framework it is expected that cultures with different values and perceptions will have different motivation towards the same tourism experience. Later, it would also lead to differences in satisfaction evaluation, as seen in Stone \& Nyaupane (2019). When discussing Japanese tourists, attributes as service quality, responsiveness, and being on time were discussed as important drivers when assessing satisfaction (Donthu \& Yoo, 1998). However, in accordance with the suggestion that motivation plays a significant role in determining the tourists' satisfaction, an examination of the correlations between the tourists' group and satisfaction should be done when controlling the dimension of their motivation to visit the destination. Without such examination, it will be impossible to determine the impact of the tourist group (domestic versus in- 
bound) over the tourism experience satisfaction.

While a better understanding of NBT trends is needed (Cope, Doxford, \& Probert, 2000), and as values, believes, and decision-making processes are shaped by national cultures (Hofstede, 1991), the differences between domestic and international tourists who visit Satoyama destinations and their satisfaction levels should be studied in light of their initial motivation to visit the destination. Therefore, to gain a comprehensive understanding of NBT visitors' behavior, and examine cultural differences between Japanese and non-Japanese visiting Satoyama areas, it is essential to look into Japan's NBT travelers' satisfaction while examining if they have had different motivations to visit the destination, and distinguished satisfaction levels from their experience. In order to do so, an examination of the correlations between the tourist group (domestic versus international) and the satisfaction level should be done when the motivation is set as a mediating factor.

\section{Research Methodology}

To examine the differences between domestic and international tourists in their motivation and satisfaction level, data was collected in convenient sampling via a questionnaire survey. The first part of the questionnaire examined the demographics and travel experience of the participants. Thereafter, tourism motivation and tourism satisfaction questionnaires followed. The measurement of the motivation to travel was carried out by examining the push and pull factors. The push factors are the internal drives that "push" the individuals to travel, while the pull factors mainly relate to the destination's attributes (Dann, 1981; Yuan \& McDonald, 1990; Uysal \& Jurowski, 1994). The tourism motivation questionnaire had 26 items: 13 push items were adapted from earlier tourism motivation studies (Kim, Guo, Wang, \& Agrusa, 2007; Pearce \& Lee, 2005; Zhang \& Peng, 2014), while some were adjusted for this current study and its setting. The same adaptation was applied to 13 pull items from Zhang \& Peng (2014), similarly, some were adjusted for this current study. Tourists' satisfaction level was examined using 27 items: 26 items corresponded with the motivational items, as conducted in previous studies that examine the correlations between tourism motivation and satisfaction (Ross \& Iso-Ahola, 1991). Item number 27 was added to measure the general satisfaction from the hosts, based on a previous study showing this item was found independent from motivation factors (Devesa, Laguna, \& Palacios, 2010). Both questionnaires had 5-point Likert scale items: $1=$ strongly disagree, 2 = disagree, $3=$ neutral, $4=$ agree, 5 = strongly agree.

Questionnaires were distributed in three languages: English, Japanese, and Chinese. Both the Japanese and Chinese versions were crossed-translated to English to minimize translation mistakes and misunderstandings. The questionnaires were distributed in two NBT Satoyama locations in Japan during December 2019 and January 2020: Ogimachi in Shirakawa-Go, Gifu Prefecture, and Kayabuki no Sato in Miyama, Kyoto Prefecture. The questionnaires were distributed for two days in each location. In Shirakawa-Go, the research- 
er asked visitors who waited for the bus to fill the questionnaire in random sampling, and in Miyama, the researcher together with a group of five students were asking visitors to fill the questionnaires near the village's parking. A small present (hand-warming bags or candy) was handed to all participants after filling the questionnaires as an act of gratitude; however, participation was done voluntarily.

\section{Findings}

373 questionnaires were collected: 85 in Shirakawa-go, and 288 in Miyama, however, only 358 questionnaires were valid for analysis. The group size of the sample is balanced with 181 domestic tourists and 177 international tourists. Most of the respondents traveled from other East Asian countries including Taiwan (70), China (39), Hong Kong (20), Indonesia (8), and seven other Asian countries (24). 16 respondents traveled from non-Asian countries, including Argentina, Australia, New Zealand, and West-European countries. Together with the domestic group, data consists of participants traveling from 20 different countries.

Gender was balanced with 180 females, 176 males, and 2 "not disclosed". Age groups were also balanced with between 16 and 40 participants in every age group. However, there were more senior Japanese (age 60 and above) in the Japanese sample.

To examine the validity of the motivation and satisfaction questionnaires, exploratory factor analyses have been conducted (see Table 1 and Table 2). Factor analysis explains $47.90 \%$ of the variance of the motivation questionnaire and $53.68 \%$ of the variance of the satisfaction questionnaire. Cronbach's alpha coefficient resulted in a robust value for the final motivation questionnaire (.905), as well as for the satisfaction questionnaire (.927). 18 out of 20 items found to be a part of either of the three factors in the motivation questionnaire had their parallel satisfaction item in the same factor out of the three satisfaction factors. These two items, "shop the local products" and "enjoy the local culture" did not load to any satisfaction factor as their loading is lower than .5 .

Then, to examine if a given motivation factor predicts the parallel satisfaction factor, three linear regressions were conducted. In the first regression, the dependent satisfaction factor "nature \& locality" was regressed to the parallel motivation factor "nature \& locality". The model was found significant $[\mathrm{F}(1.356)=$ $370.698, p=.00$ ] and explains $50 \%$ of the variance (see Figure 1). The regression of the dependent satisfaction factor "people and activity" was also found significant with the parallel motivation factor $[\mathrm{F}(1.356)=41.862, p=.00]$, and explains $10 \%$ of the variance. Lastly, the dependent satisfaction factor "experience" was found significant with the parallel motivation factor $[\mathrm{F}(1.356)=47.732, p=.00]$, and explains $11 \%$ of the variance. Therefore, all motivation factors were found as predictors of their parallel satisfaction factors. In these three regressions the motivation factors were found as predictors of the parallel satisfaction factor. As the motivation was higher, the satisfaction was higher. 


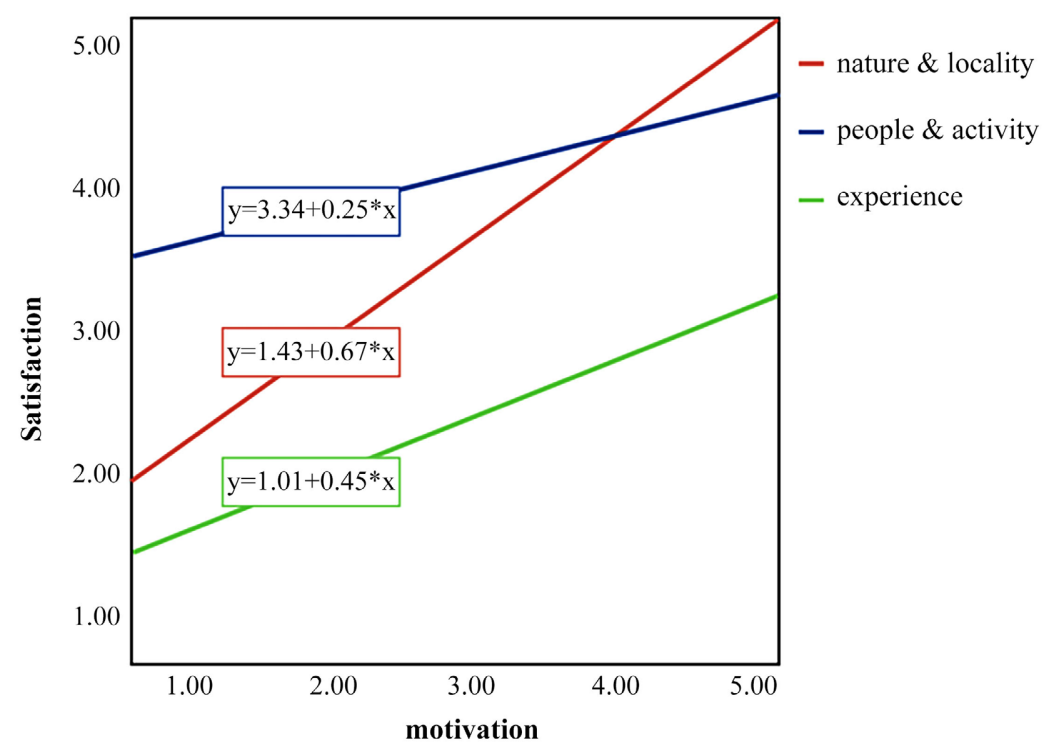

Figure 1. Linear regression of the satisfaction factors regressed to the motivation factors.

Table 1. Exploratory factor analysis for the motivation questionnaire.

\begin{tabular}{|c|c|c|c|}
\hline & Nature \& locality & \multicolumn{2}{|c|}{ People \& activity Experience } \\
\hline Experiencing natural environment & .782 & & \\
\hline A place with good atmosphere & .759 & & \\
\hline Enjoy scenery of rural Japan & .709 & & \\
\hline A peaceful and safe place & .676 & & \\
\hline Suitable for travel with family/friends & .637 & & \\
\hline Experiencing rural culture & .634 & & \\
\hline Visiting the mountain side & .627 & & \\
\hline Enjoy the local culture & .614 & & \\
\hline Trying local food & .558 & & \\
\hline Shop local products & .530 & & \\
\hline Scenery viewing & .524 & & \\
\hline Place for future living & & .797 & \\
\hline Visiting friends/relatives & & .745 & \\
\hline Meeting new people & & .723 & \\
\hline Fulfilling my dream & & .624 & \\
\hline Outdoor activities & & .527 & \\
\hline Having more travel experience & & & .718 \\
\hline Experiencing something different & & & .705 \\
\hline Broaden my knowledge & & & .680 \\
\hline Visiting a new place & & & .632 \\
\hline$\%$ of variance & $21.49 \%$ & $13.54 \%$ & $12.87 \%$ \\
\hline Cronbach's alpha & .887 & .792 & .757 \\
\hline
\end{tabular}


Table 2. Exploratory factor analysis for the satisfaction questionnaire.

\begin{tabular}{|c|c|c|c|}
\hline & nature \& locality & people \& activity & experience \\
\hline Enjoy travel with family/friends & .768 & & \\
\hline Being in a peaceful place & .725 & & \\
\hline Natural environment in the location & .689 & & \\
\hline The atmosphere in the location & .688 & & \\
\hline Enjoy being with family/friends & .650 & & \\
\hline Rural Japan scenery in the location & .616 & & \\
\hline Visiting the location & .604 & & \\
\hline Resting and relaxing & .602 & & \\
\hline Cultural aspects of the location & .587 & & \\
\hline Viewing the scenery & .576 & & \\
\hline Treatment received by the host & .516 & & \\
\hline Having no stress and pressure & .509 & & \\
\hline Food in the location & .501 & & \\
\hline Visiting the mountain & .500 & & \\
\hline Visiting friends/family & & .786 & \\
\hline Meeting new people & & .769 & \\
\hline Place for future living & & .761 & \\
\hline Outdoor activities & & .604 & \\
\hline Achieving what I wanted for a long time & & .539 & \\
\hline A new experience & & & .746 \\
\hline Experiencing something different & & & .717 \\
\hline Broaden my knowledge & & & .690 \\
\hline Visiting a new place & & & .670 \\
\hline Feeling excitement & & & .562 \\
\hline$\%$ of variance & $23.41 \%$ & $16.30 \%$ & $13.96 \%$ \\
\hline Cronbach's alpha & .911 & .833 & .812 \\
\hline
\end{tabular}

The research question, whether motivation is a mediator between the tourist group and satisfaction, was then examined. $\mathrm{R}^{2}$ of the regression model for the satisfaction of the tourist group, mediated by the motivation level is $60 \%$. Motivation fully mediates the effect of domestic/international on satisfaction $(p<.000)$. The confidence interval for the motivation variable does not contain 0 (out of 2000 samples, the effect is found between -.1308 and -.3474), therefore, the mediator is significant (see Table 3 and Figure 2). Hence, there is no significant difference between the satisfaction level of each group (domestic and international tourists) if motivation is set as a mediator. Then, the motivation of the domestic tourists is lower than the international tourists' motivation, hence, the domestic tourists' satisfaction is lower as well. 
Table 3. Regression model for predicting satisfaction by tourist group, mediated by motivation.

\begin{tabular}{|c|c|c|c|c|c|c|c|c|}
\hline & \multicolumn{8}{|c|}{ Dependent variable } \\
\hline & \multicolumn{4}{|c|}{ Motivation $^{1}$} & \multicolumn{4}{|c|}{ Satisfaction ${ }^{2}$} \\
\hline & & & Direct effect & & Indirect effect & & Total effect & \\
\hline $\begin{array}{c}\text { Independent } \\
\text { variable }\end{array}$ & $\mathrm{b}(\mathrm{SE})$ & $P$ & $\mathrm{~b}(\mathrm{SE})$ & $p$ & $\mathrm{~b}(\mathrm{SE})$ & $\begin{array}{c}95 \% \text { bootstrap CI } \\
\quad(\mathrm{n}=2000)\end{array}$ & $\mathrm{b}(\mathrm{SE})$ & $p$ \\
\hline $\begin{array}{c}\text { group, } \\
1=\text { domestic } \\
0=\text { international }\end{array}$ & $-.2927(.0575)$ & .00 & $-.0185(.0402)$ & .6458 & $-.2329(.0511)$ & $-.3408 ;-.1374$ & $-.2513(.0599)$ & .00 \\
\hline motivation & & & $.7955(.0358)$ & .00 & & & & \\
\hline
\end{tabular}

${ }^{1} \mathrm{R}^{2}=.0679 ; p=.00 ;{ }^{2} \mathrm{R}^{2}=.6016 ; p=.00$.

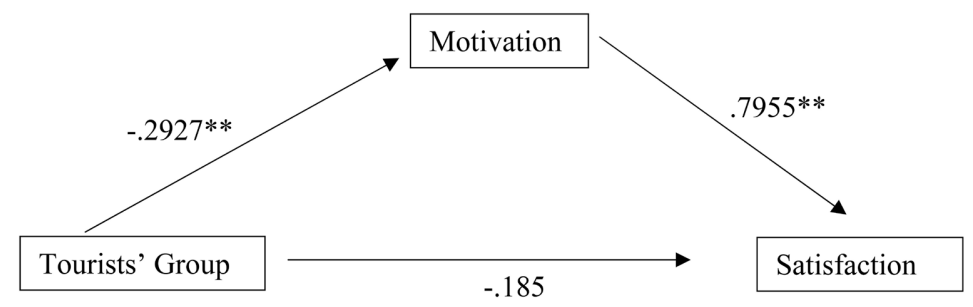

Figure 2. Regression model for predicting satisfaction by tourist group, mediated by motivation. Domestic tourists $=1$, international $=0 .{ }^{* *}<.001$.

\section{Discussion}

Results support the conjecture that the motivation fully mediates the correlation between the tourist group and the satisfaction level. The satisfaction level of Japanese tourists coming to Satoyama is significantly lower than the satisfaction of international tourists, however, this correlation is largely dependent on the motivation of the tourist group. Arguably, since the overall motivation of the Japanese tourists was lower to begin with, their satisfaction from the visit was found to be lower as well. These results support the assumption that motivation is an integral variable in which satisfaction from NBT tourism and the differences between domestic and inbound tourists cannot be fully understood without its examination.

Tourists' motivation was divided into three factors: nature and locality, people and activity, and experience, which were found, in turn, significantly correlated to the same three factors of satisfaction. Hence, we can confidently state that the satisfaction presented by the participants in this study is a direct outcome of their motivation before visiting the Satoyama destination.

Significant differences between domestic and international tourists were found both in the motivation to visit the NBT destination and the satisfaction they had when visiting as expected according to the cultural differences indicated in Hofstede studies (1991, 2001; Hofstede \& Minkov, 2010). Furthermore, these results are consistent with other studies that have reported the positive correlation between NBT visitors' motivation and satisfaction (Devesa, Laguna, \& Palacios, 2010), and the differences in tourist gaze between domestic and in- 
ternational tourists visiting NBT destinations (Stone \& Nyaupane, 2019). In this research too, consistency was found between the satisfaction factors and the factors that motivated tourists to visit the destination in the first place.

The differences found between the domestic and international tourist groups are assumed to originate in the values and perception differences between the Japanese and inbound visitors'. Assuming these two elements form the motivation, as indicated in Gnoth (1997) framework, and given that the motivation levels significantly differed between the two groups, it is argued that the motives of the two groups were divergent to begin with. These differences, in motives and later in values and perception, are assumed to be the effect of cultural differences.

Apart from the theoretical framework, there might be more explanations to the differences between the two groups both in the motivation as well in the satisfaction level. First, the fact that the motivation of international tourists was recorded as higher than the domestic tourists can be attributed to the notion that the most important push motivation factor for overseas travel is "relaxation and pleasure-seeking", as it was found continuously in different studies (Dann, 1977; Brewer, 1984; Kozak, 2002; Jönsson \& Devonish, 2008). While Japanese tourists traveling to Satoyama destinations might have lower expectations regarding the relaxation and pleasure their visit will result in, motivation items such as "Resting and relaxing" and "Having no stress and pressure" are expected to rank lower than those of international tourists. The second explanation could be found in the notion that Japanese NBT visitors are traveling not only to achieve enjoyment but also for learning and communing (Krag \& Prebensen, 2016), which are motivation factors that the current study did not explicitly investigate. In a future study, in-depth interviews should be conducted to gain a comprehensive understanding of more motivation factors that push and pull Japanese tourists to visit Satoyama destinations.

A third explanation relates to the differences between the elderly age groups in the domestic and international tourist samples. There were 37 domestic participants aged 60 and older, but only 4 participants in this age group among international tourists, while group size was 181 for domestic and 177 for international tourists. Some researchers suggest that physical, psychological, and socioeconomic changes that this generation tends to go through affect their motivation and behavior, and eventually may result in differences between elderly tourists and the younger generation in the way they interpret the meaning and importance of their travel experience (Ryu, Hyun, \& Shim, 2015: p. 326). Comprehensive research examining the older generation's motivation push factors, with a similar framework to the research conducted by Xu \& Chan (2016), could better investigate this suggestion. Concentrating on the moderation effect of the motivation push factors, as done in Xu \& Chan (2016) research, could better investigate this explanation suggestion.

\section{Conclusion}

In this study, domestic Japanese tourists who visited Satoyama destinations were 
compared to international tourists from various countries. Some traveled from Western countries, and others from East Asian countries. Although differences between countries in the Western and Eastern regions are not underestimated, similarities might be found as well (as in Choi \& Chu, 2000). In order to find more specific segments and comprise dimensions of motives for each nationality, a larger sample of each nationality is advisable. Such research would assist local authorities and stakeholders in developing better tourist retention strategies through the investigation of both domestic and international tourists' needs in Satoyama destinations, and in meeting specific interest fields and needs for each nationality. Furthermore, since the use of nationality and/or country might face criticism of generalizing nations, as mentioned by Dann (1993), it is also suggested to examine differences between domestic and international tourists when studying the perception of the destination in different age groups and genders. Also, it is important to note that the correlation between motivation and satisfaction can also be mediated or moderated as seen in the past (Battour et al., 2017; Lin \& Chuang, 2021). As the focus of the Japanese tourism industry is shifting from the iconic destinations, like Tokyo and Kyoto, to more experience-based tourism (Andonian et al., 2016), such a study would help those who plan the marketing strategy for NBT destinations in Japan, to attract not only Japanese but also international tourists.

\section{Conflicts of Interest}

The author declares no conflicts of interest regarding the publication of this paper.

\section{References}

Andonian, A., Kuwabara, T., Yamakawa, N., \& Ishida, R. (2016). The Future of Japan's Tourism: Path for Sustainable Growth towards 2020. McKinsey Japan and Travel, Transport and Logistics Practice. https://www.mckinsey.com

Armstrong, R. W., Mok, C., Go, F. M., \& Chan, A. (1997). The Importance of Cross-Cultural Expectations in the Measurement of Service Quality Perceptions in the Hotel Industry. International Journal of Hospitality Management, 16, 181-190. https://doi.org/10.1016/S0278-4319(97)00004-2

Batra, A. (2008). Foreign Tourists' Perception towards Personal Safety and Potential Crime While Visiting Bangkok. Anatolia, 19, 89-101. https://doi.org/10.1080/13032917.2008.9687055

Battour, M., Ismail, M. N., Battor, M., \& Awais, M. (2017). Islamic Tourism: An Empirical Examination of Travel Motivation and Satisfaction in Malaysia. Current Issues in Tourism, 20, 50-67. https://doi.org/10.1080/13683500.2014.965665

Boo, E. (1990). Ecotourism: The Potentials and Pitfalls (Volume 1). World Wildlife Fund.

Brewer, J. D. (1984). Tourism and Ethnic Stereotypes: Variations in a Mexican Town. Annals of Tourism Research, 11, 487-501. https://doi.org/10.1016/0160-7383(84)90033-1

Brown, S. (2005). Travelling with a Purpose: Understanding the Motives and Benefits of Volunteer Vacationers. Current Issues in Tourism, 8, 479-496. 
https://doi.org/10.1080/13683500508668232

Chakraborty, A., \& Asamizu, M. (2014). Revitalizing Japan's Mountainous Areas through Green Tourism: A Human Geographical Perspective. Issues in Social Science, 2, 58-77. https://doi.org/10.5296/iss.v2i1.5340

Chen, B., Nakama, Y., \& Zhang, Y. (2017). Traditional Village Forest Landscapes: Tourists' Attitudes and Preferences for Conservation. Tourism Management, 59, 652-662. https://doi.org/10.1016/j.tourman.2016.09.007

Choi, T. Y., \& Chu, R. (2000). Levels of Satisfaction among Asian and Western Travelers. International Journal of Quality \& Reliability Management, 17, 116-132. https://doi.org/10.1108/02656710010304537

Cope, A., Doxford, D., \& Probert, C. (2000). Monitoring Visitors to UK Countryside Resources the Approaches of Land and Recreation Resource Management Organizations to Visitor Monitoring. Land Use Policy, 17, 59-66. https://doi.org/10.1016/S0264-8377(99)00035-6

Danaher, P. J., \& Arweiler, N. (1996). Customer Satisfaction in the Tourist Industry: A Case Study of Visitors to New Zealand. Journal of Travel Research, 35, 89-93.

Dann, G. (1993). Limitation in the Use of "Nationality" and "Country of Residence" Variables. In D. Pearce, \& R. Butler (Eds.), Tourism Research: Critiques and Challenges (pp. 88-112). Routledge.

Dann, G. M. (1977). Anomie, Ego-Enhancement and Tourism. Annals of Tourism Research, 4, 184-194. https://doi.org/10.1016/0160-7383(77)90037-8

Dann, G. M. (1981). Tourist Motivation an Appraisal. Annals of Tourism Research, 8, 187-219. https://doi.org/10.1016/0160-7383(81)90082-7

Devesa, M., Laguna, M., \& Palacios, A. (2010). The Role of Motivation in Visitor Satisfaction: Empirical Evidence in Rural Tourism. Tourism Management, 31, 547-552. https://doi.org/10.1016/j.tourman.2009.06.006

Donthu, N., \& Yoo, B. (1998). Retail Productivity Assessment Using Data Envelopment Analysis. Journal of Retailing, 74, 89-105. https://doi.org/10.1016/S0022-4359(99)80089-X

Frumkin, H., Bratman, G. N., Breslow, S. J., Cochran, B., Kahn Jr., P. H., Lawler, J. J., Levin, P. S., Tandom, P. S., Varanasi, U., Wolf, K. L., \& Wood, S. A. (2017). Nature Contact and Human Health: A Research Agenda. Environmental Health Perspectives, 125, Article ID: 075001. https://doi.org/10.1289/EHP1663

Fujita, R., Terui, M., Araki, T., \& Naito, H. (2017). An Analysis of the English Communication Needs of People Involved in Tourism at Japanese Rural Destinations. Journal of Global Tourism Research, 2, 53-58. https://doi.org/10.37020/jgtr.2.1 53

Furukawa, K., \& Tomokiyo, T. (2003). A Study of the Various Associations Supporting Life of the Old People in an Aging and Depopulated District. Journal of Architecture and Planning (Transactions AIJ), 68, 77-84. (In Japanese) https://doi.org/10.3130/aija.68.77 2

Gnoth, J. (1997). Tourism Motivation and Expectation Formation. Annals of Tourism Research, 24, 283-304. https://doi.org/10.1016/S0160-7383(97)80002-3

Haahti, A., \& Yavas, U. (1983). Tourists Perceptions of Finland and Selected European Countries as Travel Destinations. European Journal of Marketing, 17, 34-42. https://doi.org/10.1108/EUM0000000004833

Hall, E. T., \& Hall, M. R. (1987). Hidden Differences: Doing Business with the Japanese. Anchor Books.

Hartig, T., Mitchell, R., De Vries, S., \& Frumkin, H. (2014). Nature and Health. Annual 
Review of Public Health, 35, 207-228.

https://doi.org/10.1146/annurev-publhealth-032013-182443

Hasan, E. U. (2017). Nature-Based Tourism and Revitalization of Rural Communities in Japan: An Ethnographic Case Study of Oyama Town. Journal of Social Science Studies, 4, 140-159. https://doi.org/10.5296/jsss.v4i1.10189

Henderson, J. C. (2017). Destination Development: Trends in Japan's Inbound Tourism. International Journal of Tourism Research, 19, 89-98. https://doi.org/10.1002/jtr.2088

Hofstede, G. (1991). Cultures and Organizations: Software of the Mind. McGraw Hill.

Hofstede, G. (2001). Culture's Consequences: Comparing Values, Behaviors, Institutions and Organizations across Nations. Sage Publications.

Hofstede, G. (2011). Dimensionalizing Cultures: The Hofstede Model in Context. Online Readings in Psychology and Culture, 2. https://doi.org/10.9707/2307-0919.1014 http://scholarworks.gvsu.edu/orpc/vol2/iss1/8

Hofstede, G., \& Minkov, M. (2010). Long- versus Short-Term Orientation: New Perspectives. Asia Pacific Business Review, 16, 493-504. https://doi.org/10.1080/13602381003637609

Ibrahim, E. E., \& Gill, J. (2005). A Positioning Strategy for a Tourist Destination, Based on Analysis of Customers' Perceptions and Satisfactions. Marketing Intelligence \& Planning, 33, 172-188. https://doi.org/10.1108/02634500510589921

Jönsson, C., \& Devonish, D. (2008). Does Nationality, Gender, and Age Affect Travel Motivation? A Case of Visitors to the Caribbean Island of Barbados. Journal of Travel \& Tourism Marketing, 25, 398-408. https://doi.org/10.1080/10548400802508499

Kim, S. S., Guo, Y., Wang, K. C., \& Agrusa, J. (2007). The Study Motivations and Study Preferences of Student Groups from Asian Nations Majoring in Hospitality and Tourism Management Programs. Tourism Management, 28, 140-151.

https://doi.org/10.1016/j.tourman.2005.11.003

Kozak, M. (2002). Comparative Analysis of Tourist Motivations by Nationality and Destinations. Tourism Management, 23, 221-232.

https://doi.org/10.1016/S0261-5177(01)00090-5

Krag, C. W., \& Prebensen, N. K. (2016). Domestic Nature-Based Tourism in Japan: Spirituality, Novelty and Communing. In Advances in Hospitality and Leisure (pp. 51-64). Emerald Group Publishing Limited. https://doi.org/10.1108/S1745-354220160000012003

Lee, C. K., Lee, Y. K., \& Wicks, B. E. (2004). Segmentation of Festival Motivation by Nationality and Satisfaction. Tourism Management, 25, 61-70. https://doi.org/10.1016/S0261-5177(03)00060-8

Lin, C., \& Chuang, Y. (2021). A Study of Participation Motivation, Experience and Satisfaction in Camping Tourists. Open Journal of Applied Sciences, 11, 190-201. https://doi.org/10.4236/ojapps.2021.112013

Maeda, T. N., Yoshida, M., Toriumi, F., \& Ohashi, H. (2018). Extraction of Tourist Destinations and Comparative Analysis of Preferences between Foreign Tourists and Domestic Tourists on the Basis of Geotagged Social Media Data. ISPRS International Journal of Geo-Information, 7, 99. https://doi.org/10.3390/ijgi7030099

Meng, F., Tepanon, Y., \& Uysal, M. (2008). Measuring Tourist Satisfaction by Attribute and Motivation: The Case of a Nature-Based Resort. Journal of Vacation Marketing, 14, 41-56. https://doi.org/10.1177/1356766707084218

Oh, Y., \& Lee, S. (2017). A Study on the Affect of Tourism Motivation on Tourism Satisfaction: Focused on Senior Tourists. International Journal of Advanced Culture Tech- 
nology, 5, 10-14.

Pearce, P. L., \& Lee, U. I. (2005). Developing the Travel Career Approach to Tourist Motivation. Journal of Travel Research, 43, 226-237. https://doi.org/10.1177/0047287504272020

Richardson, S. L., \& Crompton, J. (1988). Vacation Patterns of French and English Canadians. Annals of Tourism Research, 15, 430-435. https://doi.org/10.1016/0160-7383(88)90031-X

Ross, E. L. D., \& Iso-Ahola, S. E. (1991). Sightseeing Tourists' Motivation and Satisfaction. Annals of Tourism Research, 18, 226-237. https://doi.org/10.1016/0160-7383(91)90006-W

Ryu, E., Hyun, S. S., \& Shim, C. (2015). Creating New Relationships through Tourism: A Qualitative Analysis of Tourist Motivations of Older Individuals in Japan. Journal of Travel \& Tourism Marketing, 32, 325-338. https://doi.org/10.1080/10548408.2014.895478

Shapoval, V., Wang, M. C., Hara, T., \& Shioya, H. (2018). Data Mining in Tourism Data Analysis: Inbound Visitors to Japan. Journal of Travel Research, 57, 310-323. https://doi.org/10.1177/0047287517696960

Stone, L. S., \& Nyaupane, G. P. (2019). The Tourist Gaze: Domestic versus International Tourists. Journal of Travel Research, 58, 877-891. https://doi.org/10.1177/0047287518781890

Sung, H. Y., Morrison, A. M., \& O’leary, J. T. (2000). Segmenting the Adventure Travel Market by Activities: From the North American Industry Providers' Perspective. Journal of Travel \& Tourism Marketing, 9, 1-20. https://doi.org/10.1300/J073v09n04 01

Triandis, H. C. (1989). The Self and Social Behavior in Differing Cultural Contexts. Psychological review, 96, 506-520. https://doi.org/10.1037/0033-295X.96.3.506

Uysal, M., \& Jurowski, C. (1994). Testing the Push and Pull Factors. Annals of Tourism Research, 21, 844-846. https://doi.org/10.1016/0160-7383(94)90091-4

Wolsko, C., Lindberg, K., \& Reese, R. (2019). Nature-Based Physical Recreation Leads to Psychological Well-Being: Evidence from Five Studies. Ecopsychology, 11, 222-235. https://doi.org/10.1089/eco.2018.0076

Xu, J. B., \& Chan, S. (2016). A New Nature-Based Tourism Motivation Model: Testing the Moderating Effects of the Push Motivation. Tourism Management Perspectives, 18, 107-110. https://doi.org/10.1016/j.tmp.2016.01.001

Yuan, S., \& McDonald, C. (1990). Motivational Determinates of International Pleasure Time. Journal of Travel Research, 29, 42-44. https://doi.org/10.1177/004728759002900109

Zhang, Y., \& Peng, Y. (2014). Understanding Travel Motivations of Chinese Tourists Visiting Cairns, Australia. Journal of Hospitality and Tourism Management, 21, 44-53. https://doi.org/10.1016/j.jhtm.2014.07.001 